Special Issue: Social Cognition and Self. Citation: Navarro, S. (2015). Music and self-awareness: A relationship or not? Behavioural Sciences Undergraduate Journal, 2(1), 24-35.

Author: Serena Navarro, Psychology, Mount Royal University (MRU)

Correspondence: serena.psyc@gmail.com

Reviewers: Alain Morin, PhD, MRU; Bruce Hoffman, York University

Editor: Famira Racy, MRU

Author Acknowledgements: I would like to acknowledge my friends and family who push me to never give up and motivate me to do great things in life. I would like to specifically acknowledge Famira Racy, who has continued to inspire me with her courageous and robust spirit. I would also like to thank all the musicians who have influenced me over the years, including my Supervisor, Alain Morin, as well as my partner, Chris Neil, who has taught me to respect the nature of music but also to nurture the craft.

Copyright: (C) 2015 Serena Navarro. This is an open-access article distributed under the terms of the Creative Commons Attribution 4.0 International License. The use, distribution or reproduction of this article in other forums is permitted, provided the original author(s) or licensor are credited, a link to the licence is provided (CC for 4.0), it is indicated whether or not changes were made to the original article, and other conditions of the BSUJ and the other forums are met.

\title{
Music and Self-Awareness: A Relationship or Not?
}

\begin{abstract}
In this paper I reviewed two main themes: (1) how music can be used as a tool to increase an individual's self-awareness (SA) and (2) how music and SA relates to individual and social psychology. To investigate these themes, I searched academic databases for music and its effects on SA at the individual and group level. This paper is focused on music in the context of therapy, development, neurobiology, the relationship between bodily sensations and conscious awareness, and group or social implications. Overall, I found that there are potential future applications for music in the context of individual or group therapy. Furthermore, due to lack of specific research in this area, I explored limitations in the research and offer suggestions for future researchers trying to determine if music has an effect on individual SA.
\end{abstract}

Keywords: music, self-awareness, group-awareness, music therapy, social cognition

\section{Introduction}

Music moves the human condition beautifully. Listening to a melody or a lyric can cause a person to weep, smile, or get angry. It is in the moment of letting the sound wash over one's totality when a truth emerges. It can be a song that we relate to or a lyric that helps us understand ourselves more. This moment is called becoming self-aware. Duval \& Wicklund (1972) defined it as "when attention is directed inward and the individual's consciousness is focused on himself, he is the object of his own consciousness-hence 'objective' self-awareness" (p. 2). This review goes in depth about music, its correlations to psychology, and its effects on individuals and groups. Specifically, this literature review encompasses how music may affect a person's SA. For the purpose of this paper, music is defined as an art of sound in time that expresses ideas and emotions in significant forms through the elements of rhythm, melody, harmony and colour, and can come in many forms such as vocal, instrumental, bodily noises, and movement (Simpson \& Weiner, 1989).

I am most interested in the current research on SA and its relationship to music. Many aspects of SA (self-concept, self-regulation, self -control, self-evaluation and self-esteem) are 
explored to identify if musical experiences alter these processes (e.g., Bensimon \& Gilboa, 2010). I also explored the effects music may have on the development of individuals and how this then shapes their experience of the world and of themselves (e.g., Saarikallio, 2010; Winsler, Ducenne \& Koury, 2011). As Boxill (2007) explains, "concrete musical experiences and expression through singing/chanting, instrument playing, and music-movement promote functioning and learning on many levels of mind-body awareness” (sic; p. 102).

Mind-body awareness and functioning can alter one's personality and actions. Bensimon \& Amir (2010) proposed that musical presentation can be used as a therapeutic instrument to inspire patients to search unconscious areas of their personality, helping individuals to feel a sense of control over their thoughts and behaviours, and to increase SA. Boxill (2007) explained that her theory behind using music as a tool in therapy, one she called the 'cycle of awarenessexcitement-contact'. One has to connect to the music while listening to it to engage in this method of therapy.

Researchers believe that music has an effect on the body and mind even before the person can become consciously aware of it (Krout, 2007; Klassesn, Liang, Tjosvold, Klassen \& Hartling, 2008). The music that one is listening to is already actively stimulating the production of impulses and neurotransmitters within the many brain systems, even before one becomes fully aware of the music (Radocy \& Boyle, 2003; Krout, 2007). The brain and other parts of the body are interacting together while listening to the music and contributing to an overall effect. Boxill (2007) wrote that the therapeutic tools used in musical therapy give rise to the identification of who the client is, who we are, and what we are doing together in the musical moment, and these together are intended to heighten awareness of self, others, and the environment.

Multiple methods and terms have been used to compile information for this literature review. Article databases of peer reviewed journals, such as PsycINFO, PubMed, Google Scholar, and Academic Search Complete, were among the first sources that I searched (including both the Mount Royal University and University of Calgary databases). Music, Self-Awareness, Self-Consciousness, unconscious, awareness, consciousness, development, personality, neuroscience, music therapy, art therapy, depression, musical, listening, playing, and audience awareness were, among many other terms, used for searching these databases.

Objectives for this review were to encompass the literature that is relevant to both music and SA. This includes the development of the individual, unconscious and inner feelings, group processes, neurobiology, cognitive and behavioural processes, and psychometrics. The specific objective was to search and draw out concise conclusions on whether music has an effect on a person's SA, and if so, to explore these effects toward therapeutic treatments.

\section{Measuring the Effects of Music}

Over any number of studies, many different types of methods are used when assessing music's effects on individuals. Self-report scales, interviews, and questionnaires are used often (Bensimon \& Amir, 2010; Saarikallio, 2010; Boothby \& Robbins, 2011; Djikic, 2011; Parker, 2011; Sergeant \& Mongrain, 2011; Veltre \& Hadley, 2012). Parker (2011) clarified that qualitative interviews are used to determine specific themes from participant's explanations of music and its effects. Beck’s Depression Inventory (BDI), Geriatric Depression Scale (GDS-30), Profile of Mood State depression subscale (POMS-depression/dejection), and Depression Anxiety Stress Scales (DASS-21) are just some of the measures used to determine if music had an impact on reducing depressive symptoms in a systematic review done by Chan and associates (Chan, Wong \& Thayala, 2011). The researchers concluded that their review comprised both 
randomized controlled trials and quasi-experimental designs, but that small sample sizes and lack of clear randomized methods made firm conclusions about music and its positive effects on depression questionable.

Multiple qualitative interviews are used when assessing how music has had, if any, effects on individuals (Bensimon, Amir \& Wolf, 2008; Bensimon \& Amir, 2010; Saarikallio, 2010). Many of these interviews are done in small groups (Bensimon \& Amir, 2010; Saarikallio, 2010), which could be somewhat influenced by the social desirability bias and experimenter effects. Direct effects of music are elusive to study.

To determine if changes in the experience of one's own personality traits took place in the presence of musical or lyrical stimuli, Djikic (2011) constructed a personality change index and assessed individuals before and after the tasks by using the Big Five Inventory (BFI). The $\mathrm{BFI}$ is a 44 item questionnaire measuring the Big Five dimensions of personality (i.e., extraversion, conscientiousness, agreeableness, emotional stability/neuroticism, openness). Music enhanced self-reported variability on the BFI, but lyrics tended to suppress variability, suggesting that music opens our view of ourselves and allows for flexibility, whereas lyrics may help solidify our views of ourselves.

\section{The Relationship between Self-Awareness and Music}

Lejonclou (2009) suggested "relating experience through music to empower the clients' strength, support inner healing resources and contribute to a living bridge between body and mind” (p. 79). The act of playing music can lead to a sense of control over one's body and mind. Bensimon and colleagues (2008) sought to explain the effects of drumming and how the sound vibrations felt in the body lead to an increased awareness of body sensations. The concentration needed in keeping rhythm and timbre can increase a person's SA of what is going on emotionally, physically, and cognitively. Music was also used as a tool for pain relief in the body, suggesting that SA can be harnessed to experience bodily pleasure, or to divert unwanted sensations (Michel \& Chesky, 1995; Melzack \& Katz, 2004; Krout, 2007; Klassen et al., 2008).

\subsection{Self-awareness, Music and Social Cognition}

At the social level, the relationship of body awareness and other individual's awareness while in a musical environment can evoke certain responses. To elaborate, in social cognition, the bidirectional influence of self and others can affect how individuals act in a group setting. For example, body language and facial expressions of others influence oneself in conscious and unconscious ways, prompting us to approach or avoid others and guiding our social behaviour (Morin, El-Sayed, \& Racy, 2014). Taken together, these findings suggest that music might be a factor in increasing SA, but one must also consider other environmental effects of the social setting and individuals within it (Morin, 2004). In other words, one must ask for example, how a smile, eye contact, or hand gesture interacts with a person's cognition and therefore might influence how one interacts with another, and how this influences music exchange and viceversa.

\subsection{Musical Expectancy and Evaluative Conditioning}

Music conveys meaning and emotions by what music theoreticians deem a type of musical anticipation or expectancy effect (Vuust \& Kringelbach, 2010; Parker, 2011). That is, individuals are expecting a feeling, emotion or memory related to the music, even before listening to the music. Could this be because of emotions or memories that were associated with 
a particular music at a past event? Vuust \& Kringleback (2010) suggest that "evaluative conditioning is a form of classical conditioning; the emotional response to music listening is the conditioned stimulus" (p. 257). This implies that the relationship of music and SA could be because of the conditioning that takes place. Both the amygdala and cerebellum have been implied as subcortical brain regions that are involved in evaluative conditioning (Vuust \& Kringleback, 2010). Vuust \& Kringleback (2010) also explain that musical expectancy develops slowly over time and is not fully developed until the age of 5-11 years. Future research is needed in this area to determine, more concretely, the cause and effect relationship between music and SA.

\subsection{Neurobiology}

Music can affect our overall mood. Is it only in one's sensation of that music that the mood change happens, or is music having an effect on the brain and the rest of the body through perception? Krout (2007) proposed that, among other effects on the brain and nervous system that contribute to a positive state, music affects an individual's brain by stimulating the production of natural endorphins. This positive state potentially reinforces the precise attention given to the music while relaxed. Krout (2007) wrote that the limbic system, particularly the amygdala, has shown to be of significance in emotional and behavioural reactions to musical stimuli, and Vuust \& Kringleback (2010) also explained that brainstem reflexes play a major role in why music has an emotional effect on people. Whatever the mechanism responsible for this activation of hormones and emotional centers in the brain, it is clear that music is closely related to a physiological, neurological, and emotional network pertaining to the self.

\section{Music Therapy and Self-Awareness}

The French classical cellist Juliette Alvin pioneered music therapy in the 1960's and 1970's (Michel, 1971; Jennings, 2010). Over the last fifty years music therapy has grown exponentially (Krout, 2007), with more and more research validating music therapy and its benefits on society and the individual (Krout, 2007; Bensimon et al., 2008; Chan et al., 2011). The overarching theme of this literature review centres on music therapy, and most articles that involve music and SA revolve around some type of therapy.

\subsection{Music Therapy}

One notable example referenced in several different therapies is known as a 'contact song' that was used for nonverbal patients, individuals with some type of disability and patients with mental health disorders (Boxill, 2007; Bensimon et al., 2008; Robbins \& Piccinini, 2009). The therapist actively tries to tune in to the client and stimulate sensations that can lead to awareness and finally establish contact (Boxill, 2007). In these therapies, the contact song is the first joint musical expression, and it indicates that the client is aware of the existence of another person, in this case, the therapist. The contact song is continually being changed and is adaptable according to the current therapeutic goals (Boxill, 2007).

The contact approach to music therapy seems to have helped with many psychological goals such as happiness, wellbeing, emotional self-regulation, decreased depressive symptoms, increased self-awareness, and physical symptoms such as pain relief (Michel \& Chesky, 1995; Boxill, 2007; Krout, 2007; Bensimon et al., 2008; Bensimon \& Gilboa, 2010; Saarikallio, 2010; Chan et al., 2011). Music therapists use music to create an overall wellness effect in the space provided, overall using the connection principle between the therapist and the client in order to 
pursue the progression of the client. The most common type of music used in music therapy according to this review is classical, although folk, pop, relaxing, jazz, hip hop and lullabies are also used (Klassen et al., 2008; Chan, Chan, Mok \& Tse, 2009; Saarikallio, 2010; Veltre \& Hadley, 2012).

\subsection{Cognitive and Behavioural Therapies}

Therapies of all kinds involve many different ways of including music into a session. The most common ways of using music in therapeutic settings seem to be listening to music, creating music, playing music with a trained therapist, and playing music with a group (Bensimon et al., 2008; Bernatzky, Presch, Anderson \& Panksepp, 2011; Boothby \& Robbins, 2011; Veltre \& Hadley, 2012). While music \& self-awareness are central, there are different approaches to therapy, including client-centered, cognitive, \& behavioural approaches.

The origins of musical therapy were centered on positive psychology. The individual who is unaware of self and others is then mirrored or matched in whatever manner is needed (vocal, instrumental, bodily) in order to provide a Roger's orientated acceptance of that person (increasing mirrored stimuli increases SA because of the reflective nature of relatable mirrored feedback about the self, which then can be cognitively processed; Boxill, 2007; Schlosser, 2011). In this way, positive psychology is a precursor to using instrumentation toward SA in a therapeutic setting.

The psychology community uses music as a way to relax patients and to create a calm environment. Boxill (2007) outlined that there are many therapeutic music activities used to help patients gain awareness and self-control that is required to decrease a behaviour that interferes with everyday living. For example, music helped to decrease behaviours like perseveration with body movements in those with developmental delay, and these music activities helped patients gain the self-control needed to attain certain life skills, such as the ability to use their energy to create things instead of abusing things or people (Boxill, 2007).

There were several case studies with coma patients where musical and singing sessions of a therapist helped them to increase their awareness of the outside world (Robbins \& Piccinini, 2009). As one recovered coma patient remarked "I decided to live when I first heard the music" (Robbins \& Piccinini, 2009, p. 25). It can be considered an amazing feature of the unconscious mind to identify with the stimuli of music when in a state thought to be unaware.

\subsection{Pain Management}

Music has also been implicated by some patients as decreasing one's physical pain. The Gate Control Theory of Pain explains why listening to music may provide pain relief (Michel \& Chesky, 1995; Melzack \& Katz, 2004; Krout, 2007; Klassen et al., 2008). This theory revolves around the pain impulses that travel to and from the brain, and the bidirectional relationship for these impulses. Pain impulses travel from the site of the injury to the brain via the spinal cord, where the actual pain perception is processed (Melzak \& Katz, 2004). Multiple researchers have inferred that music blocks the impulses that travel from the injury to the brain via the ability to focus one's perception solely on the musical stimuli (Michel \& Chesky, 1995; Melzack \& Katz, 2004; Krout, 2007; Klassen et al., 2008). This research is influential because it supports the idea that humans have the ability to use attention to relieve pain (and perhaps other distress) through the direction of SA toward the experience of processing music.

The Gate Control Theory of Pain is a reminder of the body and mind reciprocal relationship, suggesting that one cannot distinguish a separation between the two. This can also 
be seen as a dualistic, yet inseparable relationship, similar to the co-dependence of nature and nurture in development. The process of listening to music and becoming self-aware is simultaneous. One might suggest that actively listening to music is bringing one into awareness of the sounds and emotions that are brought forth by music, therefore leading to a shift of awareness from the pain to the music.

\subsection{Stress, Anxiety and Depression}

I suggest both listening to and playing music can have major effects on a person's overall outlook on life. These emotions and feelings created by involvement with music are something that can be harnessed to bring about change in an individual. PTSD patients found that after a drumming session they felt relief, satisfaction, and empowerment (Bensimon et al., 2008). The drumming gave the patients access to their inner processes and feelings, enabling them to realize the weight of their emotions and memories. To elaborate, the patients said the drums evoked frightening associations of trauma, war, chase and flight. The sound and vibrations of the drums brought the patients back to a place that they had once tried to forget, and let them deal with the emotions and anger in an appropriate manner and therefore brought about a different association with the memory (Bensimon et al., 2008).

Pelletier (2004) identified 22 quantitative experimental studies examining the effects of music on stress, and the results confirmed the effectiveness of music in reducing negative mood states such as stress and anxiety. Individuals reportedly tend to feel better when in the presence of music (Krout, 2007; Boothby \& Robbins, 2011). Music has been shown to increase natural endorphins and a positive state of well-being, which may help those dealing with depression (Krout, 2007). Indeed, some researchers have found that involvement with music is associated with an increase in overall feeling of happiness and decrease in depressive thoughts (Bernatzky et al., 2011; Boothby \& Robbins, 2011; Chan et al., 2011).

\subsection{Self-awareness, Self-esteem, Self-evaluation and Self-regulation}

Music can help one access a self-aware state by becoming a useful tool throughout one's lifetime (Saarikallio, 2010). For example, music can act as a tool contributing to more selfregulation through different techniques such as revival, relaxation, mental work, and solace. Mental work through music is when one goes deeper into one's current feelings, and then, as the music unfolds one would progressively move towards a clearer and more peaceful state. This increase in SA and mental effort towards one's feelings and thoughts usually leads to an increase in self-esteem (Saarikallio, 2010). This is, in theory, because the more time spent thinking about oneself, one is able to identify and change faulty thinking and behaviours (Chan et al., 2011).

SA can lead to individuals acquiring more self-regulation and self-control. Selfregulation refers to processes of modifying and organizing various emotional, behavioural, and cognitive aspects of the self in the long term (Saarikallio, 2011; Winsler et al., 2011). Selfcontrol refers to the ability, in the short term, to control oneself, in particular one's emotions and desires, especially in difficult situations (Simpson \& Weiner, 1989). Saarikallio (2011) explained that music played an important role in emotional regulation for many patients. Individuals that listened to music tended to exhibit more self-control and were able to regulate their emotions, behaviours and thoughts better than those who did not listen to music (Saarikallio, 2011; Winsler et al., 2011).

Involvement with music has many beneficial associations, such as increasing subjective feelings of happiness and lowering signs of depression (e.g., Chan et al., 2011). High global self- 
esteem is also associated with happiness and well-being, and is defined as a positive overall evaluation of the self (Saarikallio, 2010). Self-esteem and self-evaluation are contributors to selfregulation, although the exact nature of the relationship is unknown (Morin, El-Sayed, \& Racy, 2014). Those who have distorted SA may have negative self-esteem or self-evaluations and may therefore have deficits in self-regulation. If music enhances more accurate SA and accurate SA is involved in processes related to self-regulation, then music may also facilitate self-regulation through these contributing factors.

Listening to and playing music can increase the awareness of one's own body and emotions and SA, which is the first step to being able to have control over them. For example, patients with Post Traumatic Stress Disorder (PTSD) were able to control their feelings more by controlling the rhythm, volume, tempo, and timbre of their drumming (Bensimon et al., 2008). The actual perceived control of an instrument or of one's body can give one a sense of control and agency in many other aspects of life. As Boxill (2007) explained, the therapeutic strategies bring the client into an awareness of the sound of music, and environment and mobilize what she calls “organismic energy" (physical, mental, and emotional) for action.

\section{Music on Development and Inner Feelings}

The developing person is one in which the brain is being partially shaped by the experiences one encounters. Both art and music have been shown to bring awareness to one's emotions and personality traits (Djikic, 2011; Vuoskoski \& Eorola, 2011). Music can be a very enriching tool to help one understand the progression of their development and self-concept (Djikic, 2011; Saarikallio, 2011; Vuoskoski \& Eorola, 2011). Stimuli in the environment can be processed to enhance SA (Morin, 2004) so it makes sense that musical stimuli can help illustrate moments of change and development in one's life, forever connecting music to that moment through sensation and cognitive processes related to self-awareness such as auto-biographical or self-related memory and emotions (Saarikallio, 2010; Parker, 2011).

\subsection{Early Development}

Veltre \& Hadley (2012) found that addressing issues of young adolescent girls were easier when they introduced hip hop music into their world. Focusing on the use of music to address identity formation and gender-role socialization, girls were able to empower themselves (Djikic, 2011; Veltre \& Hadley, 2012). The adolescent girls were able to create their own hip hop song and this creation had strong themes of self-knowledge, SA, and self-acceptance (Veltre \& Hadley, 2012). Parker (2011) and Saarikallio (2010) also explained that adolescent participation in music is seen as a tool toward social growth, manifestation of emotions, as well as development of character. Adolescent's engagement in music, in any shape or form, tends to lead to better self-regulation and acts as a vehicle toward ownership and independence.

\subsection{Later Development}

One might think that the brain no longer has the capacity to incorporate musical experiences into its current functionality when older. This is not the case. As one gets older the process of listening to music and playing an instrument can have a major effect on the psychological wellbeing of a person (Saarikallio, 2010). Both depression levels and blood pressure rates were decreased by listening to music in an elderly sample from Hong Kong (Chan et al., 2009). Episodic memory is connected to sensations and this includes music. By listening to a piece of music from one's past, one's awareness of certain thoughts and emotions can bubble 
to the surface once again. This cued memory, personal history, or autobiography, can give a person the insight needed to understand more about the self in the present, and illuminating one's past actions can be a sort of retrospective spotlight to things that one might not have seen at the time.

Parker (2011) explained that 'musical highs' occurred when participants sang together, feeling a sense of accomplishment and a want to experience it again. To speculate using classic behavioural principles, if one felt that one had achieved SA or accomplishment while in the presence of musical stimuli, one might search out these stimuli again because of the rewarding feeling increased SA in these contexts may bring. Thus, throughout one's lifetime one might search out again and again for that musical high and that SA consolidation as needed.

\subsection{Unconscious and Inner Feelings}

Are there unconscious thoughts and feelings that individuals can uncover through the use of music? Through musical presentation and musical playing, one can identify the emotions, thoughts, and behaviours that are involved in how one got to where one is currently at in the developmental and emotional timeline (Bensimon \& Amir, 2010). Music-making is a process where one is articulating emotion and interpersonal knowledge, and therefore engages one's selfknowledge and self-growth (Parker, 2011), which are facets of SA. As previously outlined, Bensimon et al. (2008) found that playing the drums conjured frightening associations of trauma and war in the PTSD patients, illustrating the powerful emotions that playing an intense instrument like the drums can induce from the conscious or unconscious past and bring into the self's present awareness.

\section{Individual versus Group Music Therapy}

Playing and listening to music has been a group activity for as long as sound has been around. Civilizations have used music as a tool to mark journeys in people's lives. It can represent the private and public emotions that are present at the time of these monumental occasions. Fenigstein, Scheier \& Buss (1975) have defined private self-consciousness as the focus on one's inner thoughts, feelings, motives, and emotions, whereas public selfconsciousness pertains to a general awareness of other people's responses to the self, and focuses on aspects of self that are displayed publicly (Fenigstein, Scheier, \& Buss, 1975; Bensimon \& Gilboa, 2010). The next section focuses on these private and public aspects of music and SA.

\subsection{Music Sharing, Social Cognition and Self-awareness}

Sharing music with others is a wonderful and uplifting experience. It can bring people together and can create a more harmonious and cohesive group. Bensimon \& Amir (2010) found that individuals better understand their interpersonal interactions within groups when they share their music with one another, explaining this process through the use of a SA matrix model (the Johari Window model). The model is a cognitive psychological tool used to describe the process of human interaction, and shows how music sharing can increase SA when in the presence of others through access to information about transparent behaviours, feelings, and motivations of both the presenter and the listener of the music.

\subsection{Empathy, Perspective and Inclusion}

Music that is shared, played, or listened to in a group can lead the group as a whole to better interpersonal understanding or group-awareness. The causal relationship between group- 
awareness and SA is still unknown (Morin et al., 2014) but there is strong evidence in support of a bi-directional influence between the self and others (Morin, 2004). Listening to music in a group can increase the feeling of cohesion and inclusion (Bensimon et al., 2008; Bensimon \& Amir, 2010). Veltre \& Hadley (2012) found that hip hop song exploration promoted social transformation and increased self-esteem through empowering adolescent girls to advance and respect their voices as females. Song exploration was explained as searching out hip hop songs that the girls identified with. It also fostered collaboration among the girls and built a solid female community. Other researchers have also found that children who shared their music with others showed evidence of feeling a sense of group harmony (Adler \& Fisher, 1984).

Group awareness increased when individuals participated in circle drumming and even more so when the group improvised a drum session, and promoted group interactions and cohesion in patients with PTSD (Bensimon et al., 2008). Findings of promoted group awareness, cohesion, inclusion, social transformation, and collaboration in association with sharing music add support to the idea that music increases forms of group and SA. However, the question of whether group sharing and creating of music causes collective self-awareness is still unanswered. Although the term 'collective SA' seems paradoxical, there is evidence for this phenomenon and it should therefore be further studied.

\subsection{The bi-directional Influence of Music Sharing and SA}

Based on the back and forth influences of the self on others (Morin, 2004), one can argue that 'collective SA' falls into the study of social cognition because of the bi-directional influences of people on each other's mental processes (i.e., individual SA on group awareness and vice versa). Bensimon and associates (2008) found that participants felt a sense of connection, harmony, and closeness, as well as an atmosphere of reciprocity while drumming in the circle together, suggesting the possibility that a group may collectively become SA or in tune with each other as more of a whole than as many individuals. Therefore, I argue that this feeling of harmony and connection felt together at the same time is this 'collective SA'.

Society could be seen as an organic being or reality that feeds off its own energy. What this means is that social interactions feed off of each other in a bidirectional manner. What one puts into the world, one gets out. For example, sharing a favorite song with another can be an amazing experience, especially when one experiences the joy through another's first listen. Bensimon \& Amir (2010) declared that individual SA is heightened when presenting a music selection to others that has deep personal meaning. Furthermore, audience awareness of the self enhances SA because of the self-focusing nature of self-evaluation (e.g., 'Are they judging me?' or 'Am I making a good impression?') that is linked to audience awareness of the self (Carver \& Scheier, 1978; Baldwin \& Holmes, 1987; Camilleri, 2001). The process of prepping and planning which song to present can also increase the time spent focused on aspects of SA, such as one's memories, fantasies, images and other associations (Bensimon \& Amir, 2010).

\section{Limitations in the Literature}

Many meta-analyses of music therapies do not report randomized controlled trials (Chan et al., 2011). Randomized controls are essential in identifying actual effects because without control groups, there is no baseline to compare the experimental groups to and as such no way of identifying whether or not an introduced variable makes a difference from baseline. The logistics of an experiment need to be rigorous and controlled in order for future music research to be replicated and therefore illustrate the actual results of the manipulated variables. 
Pelletier (2004) reviewed 22 quantitative studies dealing with music as a treatment for stress and found that most treatments involved muscle relaxation and imagery techniques. This showcases that other confounding factors could be contributing to the effects of decreased negative mood states. Michel and Chesky (1995) surveyed music therapists and their techniques for pain relief. They concluded that most studies did not fully report on what type of musical stimuli was used which prevented future replication. Without explicit knowledge outlining how research was conducted, other researchers will not be able to replicate the study, and again research will be lacking in efficacy.

Past research seems to indicate that many studies have confounding variables such as relaxation methods, art, and therapy-client sessions. In other words, the literature is not concretely related to music as an independent variable. Research in the future needs to focus on music as a separate and distinct variable. Further, studies also indicated that other factors such as environmental and social influences may strongly contribute to SA. Therefore, it is difficult to fully conclude that music alone can contribute to an individual's increased SA. One way to test this hypothesis in the future could be to use control groups, randomization, and controls for confounding variables in order to compare groups or individuals on SA before and after exposure to music.

\section{Future Implications of Music Sharing and Therapy}

Music in people's lives will continue to have an impact on themselves as well as society. Hopefully, society will harness the calming effects of music and implement listening stations in public places. Or, maybe someday the bus will be playing soft classical music as to incite a state of calmness during the rush hour commute. The opportunities for music to help people in society are endless, in my opinion. Group music sharing can have major impacts on society if used as a tool for inclusion and cohesion. The question remains: will society step up and use the research at hand to benefit and progress society today?

The future of music and psychology at the individual level is also limitless. Therapies of all kinds might incorporate music as a relaxation tool for patients. More specifically, music might be used in the future for anxiety prone individuals to help them focus their attention and to promote a positive state. Workplaces could use music as a break to reduce stress and encourage employees to use breathing exercises and therefore increase productivity. Using music may change the world on individual and societal levels.

\section{Conclusion}

Taken together, I conclude the findings of this review as indicative of implications for music contributing to increased SA, which can be therapeutic for groups, society as a whole, and for individuals dealing with anxiety, pain, or lack of self-focus. The psychology of music as a whole also needs to be further researched so that the theoretical knowledge can then be generalized to the individual and societal levels. These theoretical underpinnings could then be tested and applied in the areas of neurobiology, pain relief and therapy. In order to pursue this applicable path, there needs to be a progression of research dealing with music as an independent variable from other confounding variables.

Music brings people together and creates a sense of belonging and worth in the world. It can 'move mountains' as the popular saying goes. Why not harness this ability to create happiness, love, passion and awareness within the world? In my opinion, the only real reason why people are in pursuit of knowledge is to change the world for the better, and people have the 
capability of doing just that through music. At the individual level, SA is the agent to change a person and music can influence this. At the societal level, music again is the establishing factor within culture to build community and solidarity through bringing awareness to interpersonal relationships. To reiterate, people can only change when identifying with that change and music can help that process.

\section{References}

Adams, R. (Ed.). (2010). Foundations of complementary therapies and alternative medicine. Palgrave Macmillan.

Adler, R. F., \& Fisher, P. (1984). My self... through music, movement and art. The Arts in Psychotherapy, 11(3), 203-208. doi:10.1016/0197-4556(84)90040-6

Baldwin, M. W., \& Holmes, J. G. (1987). Salient private audiences and awareness of the self. Journal of Personality And Social Psychology, 52(6), 1087-1098. doi:10.1037/0022-3514.52.6.1087

Bensimon, M., \& Amir, D. (2010). Sharing my music with you: The musical presentation as a tool for exploring, examining and enhancing self-awareness in a group setting. The Journal of Creative Behavior, 44(4), 259-277.

Bensimon, M., Amir, D., \& Wolf, Y. (2008). Drumming through trauma: Music therapy with posttraumatic soldiers. The Arts in Psychotherapy, 35(1), 34-48. doi:10.1016/j.aip.2007.09.002

Bensimon, M., \& Gilboa, A. (2010). The music of my life: The impact of the musical presentation on the sense of purpose in life and on self-consciousness. The Arts in Psychotherapy, 37(3), 172-178. doi:10.1016/j.aip.2010.03.002

Bernatzky, G., Presch, M., Anderson, M., \& Panksepp, J. (2011). Emotional foundations of music as a non-pharmacological pain management tool in modern medicine. Neuroscience and Biobehavioral Reviews, 35(9), 1989-1999. doi:10.1016/j.neubiorev.2011.06.005

Boothby, D., \& Robbins, S. J. (2011). The effects of music listening and art production on negative mood: A randomized, controlled trial. The Arts in Psychotherapy, 38(3), 204-208. doi:10.1016/j.aip.2011.06.002

Boxill, E. (2007). Music therapy for developmental disabilities (2nd ed.). Austin, Texas: PRO-ED, Inc.

Camilleri, V. A. (2001). Therapist self-awareness: An essential tool in music therapy. The Arts in Psychotherapy, 28(1), 79-85. doi:10.1016/S0197-4556(00)00069-1

Carver, C. S., \& Scheier, M. F. (1978). Self-focusing effects of dispositional self-consciousness, mirror presence, and audience presence. Journal of Personality and Social Psychology, 36(3), 324-332. doi:10.1037/0022-3514.36.3.324

Chan, M., Chan, E., Mok, E., \& Tse, F. (2009). Effect of music on depression levels and physiological responses in community-based older adults. International Journal of Mental Health Nursing, 18(4), 285-294. doi:10.1111/j.1447-0349.2009.00614.x

Chan. M.F, Wong, Z., \& Thayala, (2011). The effectiveness of music listening in reducing depressive symptoms in adults: A systematic review. Complementary Therapies in Medicine, 19, (332-348).

Djikic, M. (2011). The effect of music and lyrics on personality. Psychology of Aesthetics, Creativity, and The Arts, 5(3), 237-240. doi:10.1037/a0022313

Duval, T. S., \& Wicklund, R. A. (1972). A theory of objective self-awareness. New York: Academic.

Fenigstein, A., Scheier, M. F., \& Buss, A. H. (1975). Public and private self-consciousness: Assessment and theory. Journal of Consulting and Clinical Psychology, 43(4), 522-527. doi:10.1037/h0076760

Govern, J. M., \& Marsch, L. A. (2001). Development and validation of the Situational Self-Awareness Scale. Consciousness and Cognition: An International Journal, 10(3), 366-378. Doi:10.1006/ccog.2001.0506

Klassesn, J. Liang, Y. Tjosvold,. Klassen, T., \& Hartling, L. (2008). Music for pain and anxiety in children undergoing medical procedures: A systematic review of randomized controlled trials. Ambulatory Pediatrics, 8, 117-128. 
Krout, R. E. (2007). Music listening to facilitate relaxation and promote wellness: Integrated aspects of our neurophysiological responses to music. The Arts in Psychotherapy, 34(2), 134-141. doi:10.1016/j.aip.2006.11.001

Lejonclou, A., \& Trondalen, G. (2009). 'I've started to move into my own body': Music therapy with women suffering from eating disorders. Nordic Journal of Music Therapy, 18(1), 79-92. doi:10.1080/08098130802610924

Melzack, R., \& Katz, J. (2004). The Gate Control Theory: Reaching for the Brain. In T. Hadjistavropoulos, K. D. Craig, T. Hadjistavropoulos, K. D. Craig (Eds.). Pain: Psychological Perspectives (pp. 13-34). Mahwah, NJ, US: Lawrence Erlbaum Associates Publishers.

Michel, D. E. (1971). Music therapy: An idea whose time has arrived around the world. Journal of Music Therapy, 8(3), 90-95.

Michel, D. E., \& Chesky, K. S. (1995). A survey of music therapists using music for pain relief. The Arts in Psychotherapy, 22(1), 49-51. doi:10.1016/0197-4556(94)00068-3

Morin, A., El-Sayed, A., \& Racy, F. (2014). Theory of Mind, self-awareness, and inner speech in typical and ASD individuals: A critical review. In Theory of Mind: Development in Children, Brain Mechanisms and Social Implications (pp. 43-114). Nova Science Publishers.

Parker, E. (2011). Uncovering adolescent choral singers' philosophical beliefs about music-making: A qualitative inquiry. International Journal of Music Education, 29(4), 305-317. doi:10.1177/0255761411421092

Pelletier, C. L. (2004). The effect of music on decreasing arousal due to stress: A meta-analysis. Journal of Music Therapy, 41(3), 192-214.

Radocy, R. E., \& Boyle, J. (2003). Psychological foundations of musical behavior (4th ed.). Springfield, IL US: Charles C. Thomas Publisher.

Robbins, C., \& Piccinini, J. (2009). Breathing music: A case-based presentation in three parts. In R. Azoulay, J. V. Loewy, R. Azoulay, J. V. Loewy (Eds.), Music, the Breath and Health: Advances in integrative music therapy (pp. 21-41). New York, NY US: Satchnote Press.

Saarikallio, S. (2011). Music as emotional self-regulation throughout adulthood. Psychology of Music, 39(3), 307-327. doi:10.1177/0305735610374894

Schlosser, M. (2011). Minding the music: Neuroscience, video recording, and the pianist. International Journal of Music Education, 29(4), 347-358. doi:10.1177/0255761410396966

Sergeant, S., \& Mongrain, M. (2011). Are positive psychology exercises helpful for people with depressive personality styles? The Journal of Positive Psychology, 6(4), 260-272. doi:10.1080/17439760.2011.577089

Simpson \& Weiner (1989). Music. In The Oxford English Dictionary (Vol. 10). (pp. 126-127). Walton Street, O: Oxford University Press.

Simpson \& Weiner (1989). Self-Contol. In The Oxford English Dictionary (Vol. 10). (pp. 126-127). Walton Street, O: Oxford University Press.

Veltre, V. J., \& Hadley, S. (2012). It's bigger than hip-hop: A hip-hop feminist approach to music therapy with adolescent females. In S. Hadley, G. Yancy (Eds.), Therapeutic Uses of Rap and Hip-Hop (pp. 79-98). New York, NY US: Routledge/Taylor \& Francis Group.

Vuoskoski, J. K., \& Eerola, T. (2011). The role of mood and personality in the perception of emotions represented by music. Cortex: A Journal Devoted To The Study of the Nervous System and Behavior, 47(9), 1099-1106. doi:10.1016/j.cortex.2011.04.011

Vuust, Ed: Kringelback, M., \& Berridge, K., (2010). Pleasures of the Brain: New York, University Press.

Wegner, D. M., \& Giuliano, T. (1980). Arousal-induced attention to self. Journal of Personality and Social Psychology, 38, 719-726. doi:10.1037/0022-3514.38.5.719

Winsler, A., Ducenne, L., \& Koury, A. (2011). Singing one's way to self-regulation: The role of early music and movement curricula and private speech. Early Education and Development, 22(2), 274-304. doi:10.1080/10409280903585739 